\title{
Hypothermia-induced retrograde amnesia in young and adult Swiss mice
}

\author{
Z. MICHAEL NAGY and DANIEL J. MARTIN \\ Bowling Green State University, Bowling Green, Ohio
}

\begin{abstract}
To determine whether young and adult mice were capable of recovery from hypothermia-induced retrograde amnesia, mice at 16,25 , and 100 days of age received shock for crossing from a white to a black chamber in a one-trial passive avoidance paradigm. An equal number of mice at each age received no shock for making the crossover response. Following training, half the mice in each training group received exposure to hypothermia by immersion to the neck in a cold water bath, and the remaining half were suspended over an empty water bath. All mice were given one additional daily trial for the next 6 days in the avoidance chamber, but shock was never presented. The results indicated that both young and old mice were rendered equally amnestic by the hypothermia treatment. In addition, there was no evidence of recovery from the retrograde amnesia at any age. Possible reasons for the failure to obtain recovery are discussed.
\end{abstract}

When administered shortly after training, a number of experimental treatments have produced retrograde amnesia (RA) consistently in laboratory animals. As explained traditionally by the concept of memory consolidation, RA results from a failure of memory storage (see, e.g., Jacobs \& Sorenson, 1969; Riccio, Hodges, \& Randall, 1968; Spanis \& Squire, 1987), and it has been thought by many researchers to be permanent (e.g., King \& Glasser, 1970; Luttges \& McGaugh, 1967). However, increasing numbers of studies continue to demonstrate that animals are able to recover memories thought to be lost permanently due to the amnesic treatment (see Riccio \& Richardson, 1984, for a review). For example, Quartermain, McEwen, and Azmitia (1972) reported that both rats and mice recover from electroconvulsive shock (ECS)-induced RA of one-trial passive avoidance (PA) learning if given repeated exposures to the apparatus (without shock) following the initial retest. In addition, Quartermain et al. demonstrated that such recovery was not specific to ECS, because mice also showed recovery from RA induced by cycloheximide, an inhibitor of protein synthesis. With either amnestic, lost memory for the PA task was found to recover without new training.

Schneider, Tyler, and Jinich (1974) replicated Quartermain et al. (1972) and accounted for the data by theorizing that two associations are formed during the training of the PA response. The first, involving inhibition of the punished locomotor response, is acquired through instrumental conditioning. The second association, involving conditioning of fear to the various cues in the shock chamber, occurs through classical conditioning. According to this theory, ECS disrupts only the instrumentally conditioned association-inhibition of the locomotor re-

We would like to thank James W. Burley for his assistance in testing animals. Correspondence should be sent to Z. M. Nagy, Department of Psychology, Bowling Green State University, Bowling Green, OH 43403. sponse. Thus, the animal crosses into the chamber in which it has been shocked previously. If the classically conditioned fear association remains intact, however, the animal will show increasing fear while in that chamber, and there will be a reconditioning of inhibition of the locomotor response. Thus, although the animal may appear to be recovering a lost memory as it increasingly avoids the shock chamber, Schneider et al. have argued that, in fact, a new association is established which resembles the old one in form (i.e., the animal displays inhibition of the locomotor component), rather than the recovery of a memory of the old association. Whether the return of the previously learned avoidance behavior represents the recovery of the original memory (amnesia caused by failure in memory retrieval of original learning) or the formation of a new association (amnesia caused by failure of memory storage of original learning) remains unresolved (see Riccio \& Richardson, 1984).

Our major purpose in the present study was to determine whether mice would exhibit recovery of memory following RA induced by hypothermia as has been reported for mice made amnestic through ECS or the inhibition of protein synthesis (Quartermain et al., 1972). Previous reviews of hypothermia- (e.g., Riccio et al., 1984) and ECS-induced RA studies (e.g., McGaugh, 1974) have revealed many similarities between the two amnestics in both the production and the severity of memory loss, suggesting that recovery from hypothermiainduced RA would be similar to recovery from RA induced by ECS.

A second purpose of the present study was to determine whether the susceptibility to and recovery from hypothermia-induced RA in mice varies as a function of age. Previous research examining the susceptibility to retrograde amnesia at different ages has been contradictory, with the young reported to be more, less, or equally susceptible to the effects of experimentally induced RA 
in comparison with adults. For example, Hinderliter and Riccio (1976) found that a reduction of body temperature in adult rats to approximately $21^{\circ} \mathrm{C}$ immediately after PA training resulted in marked RA. However, a similar reduction of body temperature in rats 25-31 days of age by exposure to the same hypothermia temperature as that for adults (but for a shorter duration, due to their lower body weights) did not produce RA. Surprisingly, when the young rats were exposed to a hypothermic treatment less severe than that received by the adults but that equated the rates of body temperature reduction at both ages, RA was obtained in the young rats. In a later study, it was found that the slower rate of body temperature drop during hypothermia exposure caused memory disruption in 16-day-old rats, but not in 23-day-olds (Mactutus, Concannon, \& Riccio, 1982). More recently, the 23-day-old rat has again been reported to be resistant to hypothermiainduced RA (Richardson \& Riccio, 1987). A similar agerelated difference in resistance to $\mathrm{RA}$ has been reported for the mouse (e.g., Essman, 1973). In contrast, Blozovski and Buser (1988), in a study with 16-, 18-, 20-, and 30-day-old rats, found that hypothermia caused total retrograde amnesia at all ages when the treatment was administered immediately after training. However, when the interval between training and treatment was increased, younger animals were found to be more affected by hypothermia, suggesting a greater susceptibility to RA. Finally, other studies done with the one-trial PA task have not yielded age-related differences in the susceptibility to RA between young and adult rats (e.g., Hinderliter, Blanton, \& Misanin, 1989), or between mature and aged rats (Hamm, 1981).

In the present investigation, we compared the abilities of Swiss-Webster mice of three different ages (i.e., 16, 25 , and 100 days of age) to resist hypothermia-induced RA following training on a one-trial PA task, and then examined their abilities to subsequently recover from that RA.

\section{METHOD}

\section{Subjects}

The subjects were 120 male Swiss-Webster albino mice (Mus musculus) born and reared in $30.4 \times 18 \times 12.8 \mathrm{~cm}$ polyethylene cages with wire-grid tops and wood chips on the floors. Separate groups of 40 male mice began testing at 16,25 , and 100 days of age. The mice in the 16-day-old group were unweaned; those in the older groups were weaned at 23 days of age and housed with 3 male littermates per cage. All cages were provided with ad-lib food and water and were maintained in the colony room at $24^{\circ} \pm 1^{\circ} \mathrm{C}$; all testing was conducted during the light period of the 12:12-h light:dark cycle, which began at $0800 \mathrm{~h}$.

\section{Apparatus}

Testing was conducted in a double-compartment step-through chamber constructed of $1.3-\mathrm{cm}$ plywood, with each compartment $19 \times 15 \times$ $23 \mathrm{~cm}$. The compartments, one white and one black, were separated by a like-color wall within which was a $5.5-\mathrm{cm}$-high $\times 4$-cm-wide guillotine door of clear Plexiglas. The floor in each compartment consisted of $1-\mathrm{mm}$ stainless steel rods spaced $4.5 \mathrm{~mm}$ center to center. The unconditioned stimulus (UCS) was a $2.0-\mathrm{mA}$ scrambled ac shock from a constant current source (Harvard Instrument Co., Model 3121) delivered to the grid floor of the black chamber. Training was conducted in a small room illuminated solely by a $15-\mathrm{W}$ bulb positioned $40 \mathrm{~cm}$ above the center of the apparatus.
A temperature-controlled water bath (Forma Temp, Model 2095) set at $7.2^{\circ} \mathrm{C}\left( \pm 0.02^{\circ} \mathrm{C}\right)$ was used to administer posttraining hypothermia, and an Ellab Universal Thermocouple Thermometer (Type TE3; sensitivity $\pm 0.1^{\circ} \mathrm{C}$ ) with a Type RM6 thermometer probe, $1.2 \mathrm{~mm}$ in diameter, was used to record the colonic temperatures of the mice. A series of Plexiglas cylinders, scaled to the variously sized mice, was used to restrain the mice during the hypothermia or the control conditions. The cylinders were selected to be large enough to allow the mouse to easily crawl into the open end, which was then sealed with a cork, but small enough to prevent the subject from turning over in the tube. The cylinders were perforated with small holes to allow water circulation around the mouse to ensure rapid body-temperature change. A $38.1 \times 24.1 \times 43.2 \mathrm{~cm}$ wooden chamber, maintained at $35^{\circ} \pm 2^{\circ} \mathrm{C}$ by thermostatically controlled heating elements and blower-circulated air, was used to house the mice following thermal exposure. Smaller $12.7 \times 10.2 \times 5.1 \mathrm{~cm}$ Plexiglas compartments with wire-mesh covers housed individual mice within the larger chamber.

\section{Procedure}

The basic paradigm consisted of a single PA conditioning trial followed immediately by either hypothermia or control treatment. Over the next 6 days, a single extinction trial was administered daily. The conditioning trial, administered at 16,25 , or 100 days of age, began with removal of the mouse from its home cage, weighing $(0.1 \mathrm{~g})$, and placement into the white compartment, with the mouse facing away from the lowered guillotine door. After $10 \mathrm{sec}$, the door was raised, and the latency $(0.1 \mathrm{sec})$ to cross completely (all 4 paws) into the black chamber was recorded. Following crossover, the door was lowered and a 3 -sec shock of $2 \mathrm{~mA}$ was administered to half the mice; the other half received no shock following crossover. The mice that received shock were removed from the apparatus as quickly as possible following shock, whereas those that did not receive shock following crossover were removed after they had remained in the black side for $3 \mathrm{sec}$. On the basis of the crossover latency, each mouse was assigned to one of four groups so as to make the groups within each age as similar as possible with regard to performance during original training.

Following training, half the shocked and half the nonshocked mice were then placed immediately into an appropriately sized cylinder and immersed up to their necks in the cold-water bath for $3 \mathrm{~min}$. The remaining half were also placed into restraint tubes, but were suspended over an empty water bath for the 3-min period. The mice were then removed from the bath and restraint tubes, and their colonic temperatures were recorded. They were then placed into the individual compartments in the rewarming chamber for $1 \mathrm{~h}$, after which they were returned to their home cages. Thus, there were four groups at each age: trained, hypothermia ( $\mathrm{T}-\mathrm{H})$; trained, no hypothermia (T-NH); nontrained, hypothermia (NT-H); and nontrained, no hypothermia (NT-NH). Although the litters were not split across ages, each treatment group within each age was represented by a male littermate. Thus, each age group comprised the male pups from 10 different litters.

On the retention/extinction trials that began $24 \mathrm{~h}$ following original treatment, each mouse was placed into the white compartment facing away from the raised guillotine door. Latency to cross completely into the black compartment (a maximum latency of $300 \mathrm{sec}$ was allowed) was the dependent measure. When the mouse crossed into the black compartment, the door was lowered and the mouse remained in the black compartment for $3 \mathrm{sec}$ without shock. A single trial was administered daily for 6 consecutive days, with the subject being returned to its home cage following each trial.

\section{RESULTS}

\section{Original Training Body weights}

A three-way analysis of variance (ANOVA) was conducted to determine whether the weights of the different treatment groups within each age were equivalent at the time of original training. The fact that the main effects for training treatment (T vs. NT), hypothermia treatment $(\mathrm{H}$ vs. $\mathrm{NH})$, and their interaction were not significant [all 


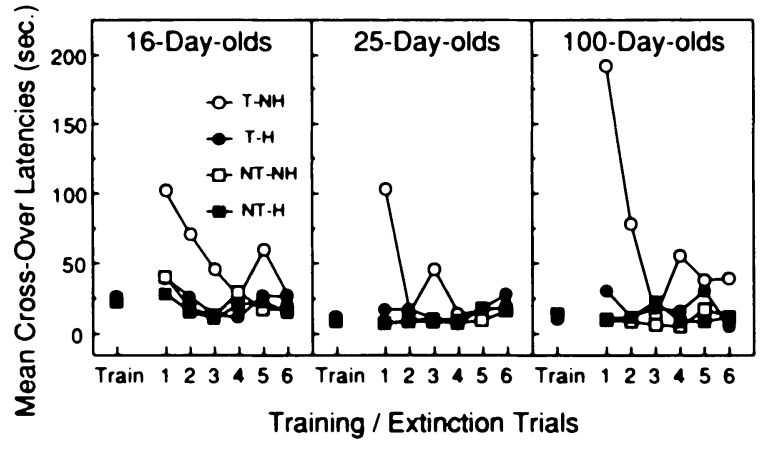

Figure 1. Mean crossover latencies for trained and nontrained mice as a function of age, hypothermia treatment, and test trials.

Fs $(1,108)<1.0]$ suggests that there were little differences in body weights among the groups within each age. There was a significant main effect of age $[F(2,108)=$ $1472.44, p<.0001]$, with the mice being significantly heavier at each older age (mean body weights were 7.7 , 14.5 , and $37.6 \mathrm{~g}$ at 16,25 , and 100 days of age, respectively; all $p \mathrm{~s}<.0001$ ).

\section{Original Training Crossover Latencies}

The mean crossover latencies during training are presented in Figure 1 as a function of treatment and age. A three-way ANOVA was conducted on the original training latencies to determine whether there were any differences in crossover latencies due to age, as well as to determine the adequacy of the matching procedure used to equate the groups within each age prior to the administration of the hypothermia treatments. The results indicated reliable differences in crossover latencies as a function of age $[F(2,108)=17.27, p<.0001]$. Individual comparisons revealed that the 16-day-old groups took longer to crossover than either the 25- or the 100-day-old groups (Scheffé tests, $p s<.05$ ), which did not differ from one another. Since the main effects of training treatment, hypothermia treatment, and all interactions involving these factors were not reliable (all $F \mathrm{~s}<1.0$ ), it may be concluded that the various groups within each age were equivalent in crossover performance prior to the administration of either the training or the hypothermia treatment.

\section{Posthypothermia Treatment Temperature}

The mean colonic temperatures measured immediately after the $\mathrm{H}$ or $\mathrm{NH}$ treatments for the three age groups are presented in Table 1. As expected, mice receiving the hypothermia treatment showed markedly lower colonic

Table 1

Mean Colonic Temperatures $\left({ }^{\circ} \mathrm{C}\right)$ of Mice Following Posttraining Hypothermia or Control Treatments as a Function of Age (in Days)

\begin{tabular}{rcc}
\hline Age & No Hypothermia & Hypothermia \\
\hline 16 & 35.6 & 19.1 \\
25 & 36.8 & 17.7 \\
100 & 37.6 & 20.7 \\
\hline
\end{tabular}

temperatures than did controls $[F(1,108)=4,665.16$, $p<.0001]$. Whereas the mean differences between groups were relatively small, the very low variability of scores within groups resulted in significant differences for the main effect of age $[F(2,108)=22.39, p<.0001]$ and the interaction of age $\times$ hypothermia $[F(2,108)=$ $9.33, p<.0002$ ]. Individual comparisons within the age $\times$ hypothermia interaction revealed that with the exception of the 25- and 100-day-old NH groups, all groups differed from one another [all $F \mathrm{~s}(1,108)>6.43$, all $p \mathrm{~s}<.05$ ].

\section{Extinction Trials}

The mean crossover latencies during extinction are presented in Figure 1 as a function of treatment and age. Examination of the data suggests that the T-NH groups at all ages had markedly longer latencies on the first extinction trial than did the three other groups, which did not appear to differ from each other. Over test trials, the latencies for the T-NH groups decreased at all ages until approximating those for the other three groups by the 2nd or 3rd day. In addition, the T-H groups appeared not to differ from the nontrained mice on any trial at any age. A four-way ANOVA conducted on the extinction crossover latencies revealed significant main effects for training group $[F(1,108)=21.75, p<.0001]$, hypothermia group $[F(1,108)=11.83, p<.0008]$, and extinction trials $[F(5,540)=14.56, p<.001]$. In addition to several significant two- and three-way interactions, the four-way interaction was significant $[F(10,540)=1.91, p<.05]$.

Individual comparisons conducted within the four-way interaction indicated that the latencies of the $\mathrm{T}-\mathrm{NH}$ groups on the 1st day of extinction were significantly longer than those for all other groups at all ages [all $F_{\mathrm{s}}(1,540)>$ 11.01 , all $p s<.001$ ], and longer than those for all other groups on the 2nd extinction day for the 16- and 100-dayold groups [all $F_{\mathrm{s}}(1,540)>5.96$, all $p s<.025$ ]. In addition, the 100-day-old T-NH group had longer latencies than did all other groups on the 4th extinction day and the 16-day-old T-NH group had longer latencies than did both nontrained groups (NT-NH and NT-H) on the 5th extinction day (all $p s<.05$ ). Comparisons among the T-H, NT-NH, and NT-H groups within each age revealed no significant differences [all $F_{\mathrm{s}}(1,540)<1.35$ ].

With regard to age-related differences in 24-h retention of one-trial PA, 100-day-old mice had significantly longer latencies than did both the 25- and the 16-day-old groups $\left[F_{\mathrm{s}}(1,540)>23.70, p \mathrm{~s}<.0001\right]$, which did not differ from one another $(F<1.0)$.

\section{DISCUSSION}

Notwithstanding the use of a similar task and experimental paradigm, our results provide little evidence for either the recovery of an original memory or the formation of a new association during repeated exposures to the apparatus following hypothermia-induced RA, in contrast to the reports of Quartermain et al. (1972) and Schneider et al. (1974). Although the reasons for the discrepancy are not clear, several possibilities should be considered before one concludes that the Swiss mouse is not capable of recovering from the effects of an amnestic treatment. First, there is the possibility of strain and/or species differences. Quar- 
termain et al. used the inbred C57BL/6J mouse, whereas we used the random-bred Swiss-Webster mouse. In addition to the obvious potentiality of learning and /or memory differences between the strains, there is also the possibility that the two strains differ in their resistance to shock. If the C57BL/6J strain had a much lower threshold to shock than did the Swiss strain, the Quartermain et al. finding that the C57BL/6J mouse did not show recovery at a low shock level of $0.16 \mathrm{~mA}$ for $2 \mathrm{sec}$ but did so at the higher level of $1.6 \mathrm{~mA}$ for $2 \mathrm{sec}$ would suggest that the Swiss mouse might display recovery if trained at a higher shock level than was used in the present study $(2 \mathrm{~mA}$ for $3 \mathrm{sec})$.

However, it seems more likely that the Swiss mouse did not learn the PA task in one trial as well as did the C57BL/6J mouse. Previous research from our laboratory (Nagy, Thaller, \& Mazzaferri, 1977) has demonstrated that the Swiss mouse shows much stronger learning at al ages (as measured by retention performance at increasingly longer train/retest intervals) when trained to a common criterion versus a single trial. In the present context, the additional exposures to the apparatus cues and shock incurred during training to a common criterion should lead to stronger conditioning of the classical (fear) component and thus increase the possibility for later recovery of the amnestic memory or for a new association to be formed. If, in fact, both the instrumentally and classically conditioned components were relatively weak following the one-trial training task, one would expect to see rather rapid extinction of inhibition of the locomotor response, resulting in more rapid crossovers into the black compartment with successive trials, as well as little recovery or reconditioning of fear during the extinction trials which is precisely what we found. If a weak conditioned fear component still existed following the amnestic treatment, the reconditioning of inhibition of the locomotor response might require more than six exposures to the fear side of the apparatus.

A second major finding in the present study was the lack of differences among the different age groups in the effectiveness of the amnestic treatment. Using age groups like those with which the young rat was found to be much more resistant to the amnestic effects of hypothermia than the adult (Hinderliter \& Riccio, 1976; Mactutus et al., 1982; Richardson \& Riccio, 1987), we found that hypothermia induced similar and marked amnesia at all ages: $\mathrm{T}$-H mice exhibited little evidence of prior training and were virtually indistinguishable from the nontrained control (NT-NH and NT-H) groups on every extinction trial. Thus, our results agree with those of Hinderliter et al. (1989), who found no agerelated differences in the susceptibility to hypothermia-induced RA in the rat on the PA task. Our results are also consistent with earlier research in which it was found that hypothermia had marked amnestic effects in both mice (Nagy, Anderson, \& Mazzaferri, 1976) and rats (Misanin, Haigh, Hinderliter, \& Nagy, 1973) as young as 9 days of age, although in these studies a multitrial escape training task was employed. Finally, we found that young mice (both 16 and 25 days of age) exhibited poorer $24-\mathrm{h}$ retention than did adult mice (100 days of age) a finding that has been reported consistently since its initial discovery by Campbell and Campbell (1962), and has generally been categorized as “infantile amnesia”' (see Riccio \& Spear, 1991; Spear, 1979; Spear, Miller, \& Jagielo, 1990, for reviews).

\section{REFERENCES}

Blozovski, D., \& BuSER, P. (1988). Passive avoidance memory consolidation and reinstatement in the young rat. Neuroscience Letters, 89, 114-119.

Campbell, B. A., \& CAmpbell, E. H. (1962). Retention and extinction of learned fear in infant and adult rats. Journal of Comparative \& Physiological Psychology, 55, 1-8.

Essman, W. B. (1973). Experimentally induced retrograde amnesia: Some neurochemical correlates. In W. B. Essman \& S. Nakajima (Ed.), Current biochemical approaches to learning and memory (pp. 159-188). Flushing, NY: Spectrum.
HАмм, R. J. (1981). Hypothermia-induced retrograde amnesia in mature and aged rats. Developmental Psychobiology, 14, 357-364.

Hinderliter, C. F., Blanton, P., \& Misanin, J. R. (1989). Preventing and alleviating hypothermia-induced amnesia in weanling and young adult rats. Behavioral Neuroscience, 103, 1200-1206.

Hinderliter, C. F., \& Riccio, D. C. (1976). Hypothermia-produced retrograde amnesia in young and adult rats. Bulletin of the Psychonomic Society, 7, 37-40.

Jacobs, B. L., \& Sorenson, C. A. (1969). Memory disruption in mice by brief posttrial immersion in hot or cold water. Journal of Comparative \& Physiological Psychology, 68, 239-244.

KING, R. A., \& GLASSER, R. L. (1970). Duration of electroconvulsive shock-induced retrograde amnesia in rats. Physiology \& Behavior, 5, 335-339.

Luttges, M. W., \& McGaugh, J. L. (1967). Permanence of retrograde amnesia produced by electroconvulsive shock. Science, 156, 408-410.

Mactutus, C. F., Concannon, J. T., \& Riccio, D. C. (1982). Nonmonotonic age changes in susceptibility to hypothermia-induced retrograde amnesia in rats. Physiology \& Behavior, 28, 939-943.

McGaUGH, J. L. (1974). Electroconvulsive shock: Effects on learning and memory in animals. In M. Fink, S. Kety, J: L. McGaugh, \& T. A. Williams (Ed.), Psychobiology of convulsive therapy (pp. 8597). Washington, DC: V. H. Winston.

Misanin, J. R., Haigh, J. M., Hinderliter, C. F., \& Nagy, Z. M. (1973). Analysis of response competition in discriminated and nondiscriminated escape training of neonatal rats. Journal of Comparative \& Physiological Psychology, 85, 570-580.

Nagy, Z. M., Anderson, J. A., \& Mazzaferri, T. A. (1976). Hypothermia causes adult-like retention deficits of prior learning in infant mice. Developmental Psychobiology, 9, 447-458.

Nagy, Z. M., Thaller, K., \& Mazzaferri, T. A. (1977). Acquisition and retention of a passive-avoidance task as a function of age in mice. Developmental Psychobiology, 10, 563-573.

Quartermain, D., McEwen, B. S., \& Azmitia, E. C., Jr. (1972). Recovery of memory following amnesia in the rat and mouse. Journal of Comparative \& Physiological Psychology, 79, 360-370.

Riccio, D. C., Hodges, L. A., \& Randall, P. K. (1968). Retrograde amnesia produced by hypothermia in rats. Journal of Comparative \& Physiological Psychology, 66, 618-622.

Riccio, D. C., \& Richardson, R. (1984). The status of memory following experimentally induced amnesias: Gone, but not forgotten. Physiological Psychology, 12, 59-72.

Riccio, D. C., \& SPEAR, N. E. (1991). Changes in memory for aversively motivated learning. In M. R. Denny (Ed.), Fear, avoidance, and phobias: A fundamental analysis (pp. 231-257). Hillsdale, NJ: Erlbaum.

Richardson, R., \& Riccio, D. C. (1987). Differential susceptibility to anterograde and retrograde amnesia treatments in preweanling rats. Behavioral Neuroscience, 101, 653-657.

SChNeIder, A. M., TyleR, J., \& JiNICH, D. (1974). Recovery from retrograde amnesia: A learning process. Science, 184, 87-88.

SPANIS, C. W., \& SQUIRE, L. R. (1987). Stability of long temporal gradients of retrograde amnesia in mice. Behavioral \& Neural Biology, 48, 237-245

SPEAR, N. E. (1979). Experimental analysis of infantile amnesia. In J. F. Kihlstrom \& F. J. Evans (Ed.), Functional disorders of memory (pp. 75-102). Hillsdale, NJ: Erlbaum.

Spear, N. E., Miller, J. S., \& Jagielo, J. A. (1990). Animal memory and learning. Annual Review of Psychology, 41, 169-211.

(Manuscript received January 11, 1993.) 